УДК 316.4.051.6

\title{
ФУНКЦИОНАЛЬНЫЕ ЭЛЕМЕНТЫ ФЕНОМЕНА СОЦИАЛЬНОЙ ПАМЯТИ
}

\section{(C) 2012 г. Э. Г. Позднякова-Кирбятьева}

\section{Харьковский национальный педагогический университет им. Г. С. Сковороды}

В статье рассматриваются ключевые функииональные элементы феномена соичальной памяти: когнитивный, эмоциональный, деятельностный, ценностный, коммуникативный, информационный. Рассматриваются процессы памяти в сочиальном контексте. Отмечается роль элиты, которая также является носителем сочиальной памяти, что выводит исследование на проблематику элиты, её места и роли в обществе как актуализатора социальной памяти.

Ключевые слова: сочииальная память; память; функииональные элементы; элита; групnы.

Key functional elements (FEs) of the social memory phenomenon, such as cognitive, emotional, valued, communicative, informative, are reviewed in the article. The processes of memory are analyzed as a part of a social context. The role of the elite, which also is the social memory transmitter, is shown, so, the another goal of the research is the elite subject matter, its places and roles in the society (as of the actualizer of the social memory).

Key words: social memory; memory; functional elements (FEs); the elite; groups.

Динамическая, процессуальная сторона ориентирует нас на рассмотрение социальной памяти как процесса деятельности. Этот процесс также структурируется через функциональные элементы. Для рассмотрения социальной памяти с использованием общепсихологических аналогий, необходимо перенести их в социальный контекст.

В общей психологии рассмотрение памяти связано с процессами памяти. Рассмотрим их последовательно.

Процесс запоминания позволяет актуальным представлениям (восприятия или воображения) перейти собственно «в память»; происходит или при однократном восприятии, или путем повторяющихся актуализаций однотипного раздражителя.

Следующий процесс - сохранение, более или менее длительное удержание в памяти некоторых сведений, имеющее две стороны: собственно сохранение и забывание.

Дальнейший процесс - воспроизведение, представляющий собой воссоздание сохраненного в памяти материала, протекающее на нескольких уровнях:

- узнавание, или воспроизведение с опорой на восприятие;

- собственно воспроизведение, не вызывающее затруднений;

- припоминание, требующее волевого усилия [5].

Теперь эти процессы индивидуальной психической жизни нужно преломить в социальном контексте, для группового субъекта.

Запоминание как попадание в социальную память наиболее сходно с индивидуальными практиками. Значимые события (созидательные или разрушительные процессы), имеющие достаточный масштаб для каждого из уровней в социальном субъекте, остаются в социальной памяти. Имеет смысл говорить о критериях запоминания - это достаточный уровень значимости (как для индивидуальной психики, так и для социальной памяти) и масштабности (для социального субъекта). Процесс запоминания в плане социальной 
памяти вербализируется в обыденной речи как фраза «попало в историю». Естественно, что в зависимости от уровня в социальном субъекте это может быть явление различного масштаба - от истории страны до семейной истории.

Сохранение как удержание в памяти является ключевым во всем процессе, особенно с учетом наличия двух противоборствующих тенденций - запоминания и забывания. Исходя из этого вопрос удержания в памяти как индивидуальной, так и групповой - имеет не просто перманентную актуальность. Она повышается с ростом объема того материала, который следует удерживать в памяти. Естественно, что социальная память (в плане сопоставления объемов материала) намного превосходит индивидуальную. Приобщение индивида к групповому опыту социально институализируется через систему образования.

Сохранение памяти осуществляется с помощью материальных носителей, совершенствование которых происходит непрерывно. Во времена отсутствия или минимального наличия таких носителей (в виде, допустим, артефактов, напоминающих о событии), материалы социальной памяти передавались устно.

Ориентируясь на функциональные элементы можно охарактеризовать в самом общем виде типы элементов социальной памяти:

- события, исторические персонажи (информационный элемент);

- трудовые навыки, технологии, научнотехнические революции, модернизация (деятельностный);

- мифы, легенды, устные истории (коммуникативный);

- идеология, мировоззрение, нормы, моральные кодексы (аксиологический элемент); - эмоциональный (чувственный).

Приведенная типология носит обобщенный характер, служит для первичной систематизации элементов социальной памяти.

Развитие материальных носителей для нужд сохранения материала в социальной памяти происходило не только в направлении увеличения объемов сохраняемого, но и повышения уровня технологичности в самом носителе. Это можно проиллюстрировать приблизительно такой цепочкой: артефакты, глиняные таблички, бумага, магнитно-пленочные носители, твердые диски, микросхемы (чипы), но этот путь не окончен - то, что занимало целую комнату лет 40 назад, умещается теперь в спичечном коробке.

Именно с материалами, внесенными на носитель, связана классификация внутри «образного» вида памяти: сохраняются зрительные образы (картины, схемы, фото), звуки, а с недавних пор - их комплексы (кино, видео). Остальные анализаторы - осязание, запах, вкус - малопригодны для непосредственного сохранения (хотя создатели фильмов и компьютерных игр настойчиво работают и в этом направлении); вместо долговременно сохраняющихся образцов люди используют репродуцирующиеся их источники (пища, одежда и т. д.).

Легче всего внести на материальный носитель материалы словесно-логического вида памяти - тексты. Более того, с помощью этого вида памяти человечество всегда пыталось увековечить материалы и по другим видам памяти - описываются действия; эмоциональные переживания и чувства; ощущения по всем анализаторам, для чего привлекаются ссылки, например, на доступные источники ощущений.

Наиболее важным процессом памяти является воспроизведение. Именно ради извлечения прошлого опыта для нужд настоящей ситуации, решения проблемы и существует память как атрибут субъекта.

Отсутствие опыта, забывание прошлых успехов или неумение извлечь и воспользоваться существенно затрудняет бытие, и поэтому воспроизведение всегда актуально как для индивидуального, так и группового субъекта. Субъекты, не пользующиеся адекватно прошлым опытом, оцениваются отрицательHO.

Понятно также и то, что первые два «уровня воспроизведения» - узнавание и воспроизведение без волевых усилий - не составляют проблем как для индивидуального, так и группового субъекта. А вот припоминание, которое по определению требует волевых усилий, составляет квинтэссенцию проблем использования прошлого опыта.

Стоит отметить, что припоминание всегда обусловлено внешней ситуацией — то ли 
потребности индивида, связанные с его жизнедеятельностью, то ли в общественной жизни для решения социальных вопросов. Особенностью социальной актуализации припоминания оказывается то, что ее источником является тот, кого назовём здесь «актуализатор социальной памяти». Можно очертить определяющие качества, которые позволяют ему осуществлять актуализацию прошлого социального опыта:

— индивидуальная способность быть носителем социальной памяти;

- действительное или мнимое превосходство в обладании социальной памятью в виде имеющихся в его распоряжении фрагментов социального группового опыта;

- явно выраженные лидерские качества, позволяющие ему активно влиять на жизнь социума не только с напоминаниями, но и с призывами прислушаться и воспользоваться прошлым опытом, чтобы оптимизировать групповую деятельность или избежать повторения ошибки.

По поводу такого лидерства в обыденном сознании укоренился стереотип, что такой субъект является «харизматической личностью». Харизматичность соотносится с коммуникативным и моральным компонентом деятельности. Можно также выделить и другие разновидности элиты, соответствующие остальным компонентам:

- интеллектуальная элита (когнитивный, информациологический элемент);

- моральный авторитет (аксиологический элемент);

- успешный человек, технократический управленец (деятельностный элемент);

— вдохновитель (эмоциональный, чувственный элемент).

Каждый из перечисленных типов элиты обеспечивают актуализацию социальной памяти в своей сфере и направлению деятельности. Интеллектуальная элита актуализирует социальную память с помощью научных трудов, исследований, публикаций. Носители морального авторитета актуализируют исконные нравственные максимы нации, народа, страны. Технократические лидеры мобилизуют преобразовательные интенции общества, апеллируя к образцам прошлого. Харизматики укрепляют свою моральную власть, обра- щаясь к заветам отцов, беря на себя миссию воплотить эти заветы в настоящее время.

Так выглядят базисные предпосылки лидерства, однако вполне можно предположить и наличие нескольких таких компонентов в одном субъекте, чему эпизодически получаем подтверждение в своем ближнем или дальнем социальном окружении.

На каждом из уровней (от лидера нации в большой группе до главы семьи в микрогруппе) в социальном групповом субъекте находятся представители элиты, претендующие на лидерство и реализующие функции актуализатора социальной памяти.

Кроме того, бывают ситуации, когда социум делегирует конкретным лицам (индивидам) быть воплощенным субъектом групповой памяти, благодаря чему сохраняется субъектность самого социума. Хотя чаще эту функцию приходится выполнять субъекту в комплексе с другими, а именно - связанными с лидерством и управлением. Налицо два явных запроса со стороны общества, которые формализуются в первом случае в роли историка, во втором - политика или руководителя.

В любом случае это масштабные в социальном плане роли, поэтому общество для этого осуществляет определенного рода селекцию, в результате чего соответствующий субъект оказывается неординарным, поднявшимся над массами. А это выводит исследование на проблематику элиты, её места и роли в обществе как актуализатора социальной памяти. Элита является также носителем социальной памяти, ответственной за её адекватное сохранение и последующую актуализацию при наступлении потребности в этом.

Индивидуальный субъект социальной памяти, будучи представителем элиты, актуализирует прошлый опыт исходя из своего понимания общественной потребности. Широкие массы могут не видеть, не осознавать этой потребности, не ощущая, например, её реальную актуальность, в отличие от этого субъекта. В этом смысле становится вопрос мотивации актуализации прошлого социального опыта.

Если рассматривать социальную ситуацию как вызов современности, который 
улавливается и становится важным и для субъекта, осознаваясь им как важный для повышения эффективности социальных преобразований, то субъект будет стремиться к тому, чтобы использовать прошлый опыт для решения современных задач. В таком контексте его деятельность может рассматриваться как «антикризисная», а её особенности - как «вызов».

С помощью функциональных элементов можно структурировать вызовы, кризисной ситуации, для решения которых мобилизуется социальная память:

- мировоззренческий кризис (когнитивный элемент);

- экономический кризис (деятельностНЫЙ);

- ценностный кризис (аксиологический);

— гуманитарный кризис (коммуникативНЫЙ);

— кризис в информационной сфере (информационный);

- кризис чувственной эпохи, в соответствии с концепцией П. Сорокина (эмоциональный).

Можно утверждать и то, что эти компоненты социальной кризисной ситуации могут актуализироваться совместно, тогда социум вынужден решать проблему приоритетов - что именно устранять в первую очередь и на что направлять максимальные усилия; что может являться инструментом такой антикризисной деятельности. В этом плане субъекты элиты склонны актуализировать элементы социальной памяти по своему усмотрению, убеждая себя и других в том, что именно эта часть социальной памяти сможет решить современные проблемы.

Процесс актуализации социальной памяти имеет двусторонний характер. С одной стороны, его инициирует, поддерживает и усиливает представитель элиты - актуализатор, с другой стороны, социальная среда может как оказывать сопротивление, так содействовать актуализации социальной памяти и использованию ее для решения современных проблем.

Роль социальной среды заключается в способности и готовности членов группы прислушаться к актуализатору социальной памяти и поддержать его усилия по включе- нию ее ресурсов для решения современных проблем. Способность социума актуализировать социальную память в определенной степени зависит от типологической характеристики сообщества, группы, от её информационного типа. Этот тип не сводится к индивидуальным особенностям членов группы, а существует в качестве эффекта синергии. Одной из номинаций информационного типа группы является «коллективное бессознательное» К. Юнга [6].

Используя классическую теорию о роли личности в истории, наиболее точно изложенную в соответствующей работе Г. В. Плеханова, можно констатировать, что в большой группе всегда найдется наиболее активный выразитель групповых интенций, которому удаётся осознать это коллективное бессознательное, и тогда члены группы в его проявлениях будут как бы «узнавать» свои неосознаваемые ранее смутные догадки и стремления [4]. Если же руководитель большой группы не соответствует этому коллективному бессознательному, то его посылы в социум, в том числе и в плане актуализации социальной памяти и апеллировании к прошлому опыту не будут встречать одобрения, и могут натолкнуться на более-менее ощутимое противодействие, вплоть до устранения от власти.

На самом деле, в реальном обществе далеко не всегда можно обнаружить полное единодушие по отношению к тому или иному вопросу. Чаще в обществе существуют группы с разным пониманием современной ситуации и того, что именно из социальной памяти может способствовать моральной мобилизации общества. Например, в современной Украине сложилась отчетливая, и пока непреодолимая поляризация в отношении вопросов советского прошлого и освободительных движений Западной Украины.

Так что в плане актуализации социальной памяти призывы «хранить традиции верных ленинцев» или «быть достойными продолжателями дела борцов за независимость Украины» служат своеобразными маркерами различных по ценностным основаниям сообществ. Причем такие различия имеют признаки антагонизма и являются источниками перманентных конфликтов.

Второй момент касается того, что ценно- 
сти и установки сменяют друг друга последовательно в течение определенных периодов времени по определенному закону [2]. Это относится и к таким длительным процессам, как особенности этногенеза, так и к циркуляции информации в рамках более-менее кратковременных циклов. Имеет значение также феномен «человеческого бессознательного», который охватывает определенную сферу памяти [1].

Процесс выглядит обобщенно как зарождение и возникновение идеи, первичная реализация идеи в упрощенном виде, получение ощутимого масштабного результата, использование как продуктивной технологии в течение длительного времени, активное использование идеи.

Интересным оказывается и взаимодействие этих двух моментов. Социальные группы, имеющие информационно-типологические характеристики консервативного плана, склонны поддерживать объемную социальную память, накопленную за длительный период времени.

Напротив, наиболее радикальными, склонными к решительной модернизации, являются жестко организованные группы с приверженностью единой идее и преследованием инакомыслия. Для этих групп более естественными являются тенденции коренного переустройства, концентрация социальной памяти на недавних отрицательных моментах, требующих полного искоренения.

Таким образом, субъект социальной памяти предстаёт как четырехуровневый по количественному критерию (микрогруппа, малая группа, конгломерат малых групп, большая группа).

Далее, то, что в общей психологии обозначено как «материал для запоминания» [3], названо здесь при перенесении на групповой субъект «предметом социальной памяти», который структурируется содержательно через системные функциональные элементы и имеет по каждому из них свою выраженность в соответствии с уровнем в групповом субъекте.

Поступила в редакцฺию
Процессы памяти, обозначенные в общей психологии как запоминание, сохранение и воспроизведение, остаются такими же и для группового субъекта. Отличительной особенностью здесь оказываются социальные условия воспроизведения, которые включают необходимость «актуализатора социальной памяти», выступающего компетентным хранителем социального опыта. Деятельность его как субъекта происходит в социальной среде, которая может способствовать или препятствовать актуализации социальной памяти.

Ключевыми функциональными элементами феномена социальной памяти выступают: когнитивный, эмоциональный, деятельностный, ценностный, коммуникативный, информационный. Социальная память также может включаться в сферу «коллективного бессознательного».

\section{Литература}

1. Гроф С. Области человеческого бессознательного. - М.: Всесоюз. центр переводов науч.-техн. документации и литературы, 1980. - $174 \mathrm{c}$.

2. Каганець I. В. Арійський стандарт: Українська ідея епохи Великого Переходу. K.: А.С.К., 2004. - 384 с.

3. Курс общей, возрастной и педагогической психологи. Вып. 3. Возрастная и педагогическая психология. / М. В. Гамезо, А. П. Гуркина, Е. Я. Гурьянова и др.; под ред. М. В. Гамезо. - М.: Просвещение, 1982. - 176 с.

4. Плеханов Г. В. Избранные философские произведения. Т. 2. - М.: Госполитиздат, 1956. - $824 \mathrm{c}$.

5. Познавательные процессы и способности в обучении: учеб. пособие для студентов пед. ин-тов. / В. Д. Шадриков и др.; под ред. В. Д. Шадрикова. - М.: Просвещение, 1990. - 142 c.

6. Юнг К. Г. Психологические типы. М.: Прогресс-Универс, 1996. - 716 с.

21 сентября 2012 г. 


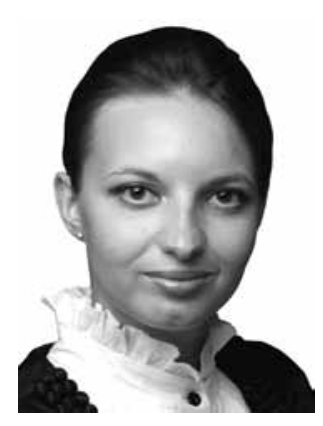

Эллина Геннадьевна Позднякова-Кирбятьева - кандидат социологических наук, докторант кафедры политологии, социологии и культурологии Харьковского национального педагогического университета им. Г. С. Сковороды.

Ellina Gennadyevna Pozdnyakova-Kirbatyeva - Ph.D., Candidate of Sociology, competitor for Doctor's degree at the Kharkov National Pedagogical University of G. S. Skovoroda name department of Political Science, Sociology and Study of Culture.

69124, Украина, г. Запорожье, ул. Курузова, 11А, кв. 82

11A Kuruzova st., app. 82, 69124, Zaporozhye, Ukraine

Тел.: + 38 (063) 316-44-99; e-mail: cobrian@mail.ru

Министерство образования и науки РФ

Федеральное государственное бюджетное образовательное учреждение высшего профессионального образования «Смоленский государственный университет»

приглашают принять участие во II Международной научно-практической конференции «Дизайн-образование в России: проблемы и перспективы развития»

К участию приглашаются ученые, преподаватели, магистранты, аспиранты, докторанты, ведущие научные исследования в области дизайн-образования.

Цель конференции: обмен научным, практическим и педагогическим опытом в сфере дизайнпедагогики; сохранение традиций в дизайн-образовании; укрепление межвузовских контактов; осуществление исследований и проектов в области дизайна.

Заявки и научные материалы принимаются по электронному адресу:

dizayn-1@yandex.ru

Тел.: +7 (4812) 38-48-93; +7 (904) 368-42-33 